\title{
Human endothelial cell response to polyurethane-gold nanocomposites
}

\author{
Tung-Tso Ho • Yu-Chun Lin • Shan-hui Hsu
}

Published online: 5 September 2012

(C) The Author(s) 2012. This article is published with open access at Springerlink.com

\begin{abstract}
Gold ( $\mathrm{Au}$ ) is long considered as a biocompatible metal, and gold nanoparticles (AuNPs $\sim 5 \mathrm{~nm}$ ) were recently reported to scavenge free radicals. The effect of Au embedded in a polymeric material is less investigated compared with that of silver. In this study, nanocomposites from polyurethane (PU) and 43.5 or $174 \mathrm{ppm}$ of AuNPs were prepared from a waterborne process. The response of endothelial cells (ECs) to the PU-Au nanocomposites was investigated in vitro and in vivo. ECs on PU-Au nanocomposites showed lamellipodia formation and better cell proliferation. The activation of proteins in ECs grown on PU-Au nanocomposites was analyzed by two-dimensional gel electrophoresis and confirmed by Western blot. The new protein identified through this procedure was valosin-containing protein (VCP), which is known to have immunomodulating effect. VCP was upregulated by PU-Au 43.5 ppm and PU-Au 174 ppm, but more in PU-Au $43.5 \mathrm{ppm}$. This suggested that the dispersion of AuNPs in the polymer matrix may be more important than the loading amount. PU-Au catheters implanted in rat blood vessels showed less foreign body reaction and more extensive EC coverage than the control PU catheters. The good in vivo biocompatibility of PU-Au may be associated with the anti-
\end{abstract}

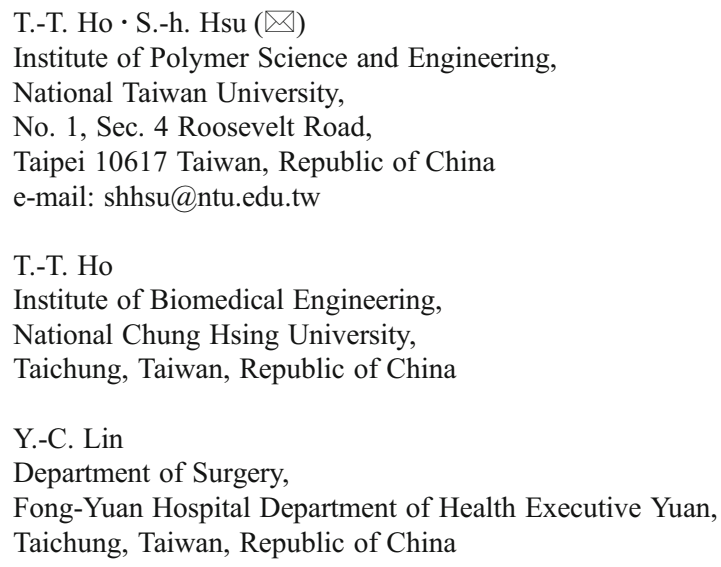

inflammatory effect of PU-Au. Based on this study, AuNPs may serve as an antioxidant additive for biomedical polymers.

Keywords Gold nanoparticles (AuNPs) · Polymer nanocomposites · Two-dimensional gel electrophoresis . Anti-inflammatory

\section{Introduction}

Recent progress in nanotechnology has brought some new insights regarding the surface design of a biomaterial. When a biomaterial is applied, it is the surface of the material that is in contact with the human body. The physicochemical features of a biomaterial in nanometric scale often have an impact on the physiological behavior of the human cells attached to its surface $[1,2]$. This concept is now widely recognized and used in designing a biomaterial surface for controlling the cell function [3-5].

Bulk gold $(\mathrm{Au})$ is an inert and biocompatible material. Gold nanoparticles (AuNPs) when added to a few biomaterials in small amounts (from several parts per million to $1 \%$ ) can modify the properties and biological performance of these materials through the introduction of nanometric surface features [6-8]. For example, polyurethane (PU), as an industrial elastic polymer with pervasive influence on modern human life, displayed a rise of thermal stability upon the addition of AuNPs $(\sim 5 \mathrm{~nm})$ and demonstrated different surface morphologies comprised of nanosized harder and softer domains [7]. A previous study showed that PU containing 43.5 ppm AuNPs may activate focal adhesion kinase (FAK) and the phosphatidylinositol 3-kinase/serine-threonine kinase (PI3K/Akt) signaling pathway in bovine endothelial cells (ECs), leading to cell proliferation and migration [9]. An overloading of AuNPs (e.g., 174 ppm) can cause the loss of the positive effect because of NP aggregation. 
Two-dimensional gel electrophoresis (2-DGE) is a core platform technology in the study of proteomics. It involves the separation of protein complex mixtures from cells or tissue by the isoelectric point $(\mathrm{pI})$ and molecular size of proteins. It has been used in many research areas such as protein analysis of mesenchymal stem cells [10], search of biomarkers [11], and detection of cell surface proteins [12].

In this study, the polymer PU and PU nanocomposites with two different doping concentrations of AuNPs were used and served as a model to investigate how the nanostructure brought about by AuNPs may have affected the protein expression levels of human umbilical vein endothelial cells (HUVECs). 2-DGE was used as a novel tool to identify new possible proteins and signaling pathways responsible for the changes of HUVEC behavior on AuNPsmodified PU. We also confirmed the better biocompatibility of this PU-Au nanocomposite in vivo.

\section{Materials and methods}

\section{Preparation of PU-Au nanocomposites}

AuNPs were manufactured by Gold Nano Tech, Inc., Taiwan. AuNPs $(\sim 5 \mathrm{~nm}$ in size $)$ were sonicated for $3 \mathrm{~h}$ at a temperature below $20^{\circ} \mathrm{C}$. The concentration of AuNPs was confirmed by inductively coupled plasma.

The PU emulsion and cross-linker were obtained from Great Eastern Resins Industrial Co., Taiwan. The PU emulsion (50\% solid content in distilled water) was synthesized using hexamethylene diisocyanate (HDI) and the macrodiol poly (butadiene adipate) (average molecular weight, 2,000) at a molecular ratio of 3:1 and chain-extended by ethylenediamine sulfonate sodium salt and ethylenediamine. The cross-linker was a mixture of the isocyanurate trimer of hexamethylene diisocyanate (HDI trimer) and $6 \%$ Bayer hardener (made from HDI trimer and polyethylene glycol). PU polymer was prepared by mixing $1 \%$ cross-linker in the PU emulsion and further dried. The chemical composition of the final PU polymer is illustrated in Scheme 1 [7]. For PU-Au nanocomposites, AuNPs were added to $10 \% \mathrm{PU}$ emulsion, so that the final concentration of AuNPs was 43.5 or $174 \mathrm{ppm}$. To fabricate materials into films, the mixture containing $0,43.5$, or $174 \mathrm{ppm}$ AuNPs was cast on 15 or $32 \mathrm{~mm}$ coverslip glass by a spin coater (PM-490, Synrex, Taiwan). The cast films were put in a $60{ }^{\circ} \mathrm{C}$ oven for $48 \mathrm{~h}$ and in a $60{ }^{\circ} \mathrm{C}$ vacuum oven for another $48 \mathrm{~h}$ to remove water. The final film samples were abbreviated as PU, PU-Au 43.5, and PU-Au 174.

\section{Cell culture}

HUVECs were purchased from Bioresource Collection and Research Center (No. H-UV001). Cells were cultured in medium M199 (Gibco) with $10 \%$ fetal bovine serum (Gibco), $25 \mathrm{U} / \mathrm{ml}$ heparin (Sigma), $30 \mu \mathrm{g} / \mathrm{ml}$ endothelial cell growth supplement (Upstate), $2 \mathrm{mM}$ L-glutamine (Gibco), and $1 \%$ penicillin/streptomycin (Gibco) in a T-flask coated with $1 \%$ gelatin (Sigma Catalog No. G-9382). The cultures were maintained in a $5 \% \mathrm{CO}_{2} / 37{ }^{\circ} \mathrm{C}$ incubator. The seeding density on material samples was $2 \times 10^{4}$ cells for each $15 \mathrm{~mm}$ diameter films (in 24-well culture plates) and $8 \times 10^{4}$ cells for each $32 \mathrm{~mm}$ diameter films (in 6-well culture plates). A blank cell tissue culture polystyrene (TCPS) served as the control.

\section{Cellular response}

HUVECs were incubated on the material for $48 \mathrm{~h}$. The seeding density was $2 \times 10^{4}$ cells for each $15 \mathrm{~mm}$ diameter material films fit in each well of 24-well culture plates. Cells were trypsinized and counted for cell proliferation using a hemacytometer combined with an inverted phase contrast microscope (TE-300, Nikon, Japan). For cytoskeleton staining, cells were incubated on the material for $16 \mathrm{~h}$, fixed with $4 \%$ paraformaldehyde (Sigma), and stained by phalloidin (Sigma). Cell morphology and cytoskeleton were examined by an optical microscope (Labophot-2, Nikon, Japan). Particularly, the number of lamellipodia was counted under the microscope. The percent chance of lamellipodia formation was defined as the number of lamellipodia divided by the total number of cell-material contacts over an area of $0.6 \mathrm{~mm}^{3}$ (more than 60 contacts for each material).

\section{Protein preparation and 2-DGE}

Proteins were extracted from cells cultured on each material for 2 days by the liquid nitrogen freezing and $37^{\circ} \mathrm{C}$ thawing process. Protein extracts were centrifuged at $13,000 \mathrm{rpm}$ and $4{ }^{\circ} \mathrm{C}$ for $10 \mathrm{~min}$ to remove particulates. Protein extracts $(200 \mu \mathrm{l})$ were added with $62.5 \mu \mathrm{l}$ of $100 \mathrm{mM}$ dithiothreitol (DTT) and $65 \mu \mathrm{l}$ of $98 \%$ trichloroacetic acid without shaking and placed in $-20{ }^{\circ} \mathrm{C}$ overnight. Protein extracts were then centrifuged at $13,000 \mathrm{rpm}$ and $4^{\circ} \mathrm{C}$ for $15 \mathrm{~min}$ to remove the supernatant. The

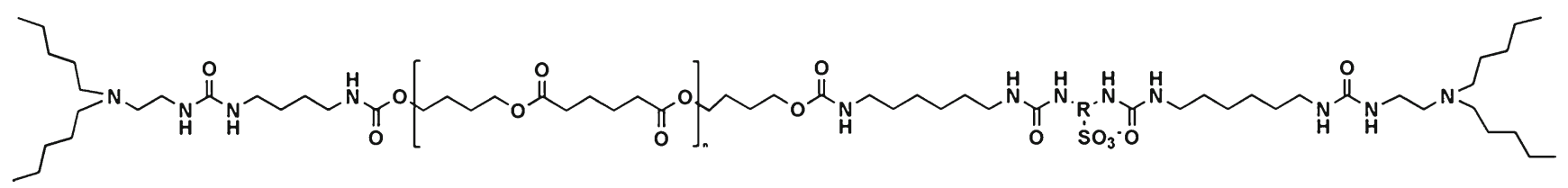

Scheme 1 The chemical composition of the PU polymer prepared in this study 
precipitation was washed by acetone at $-20^{\circ} \mathrm{C}$. The acetone was removed by centrifugation at $13,000 \mathrm{rpm}$ and $4{ }^{\circ} \mathrm{C}$ for $10 \mathrm{~min}$. Proteins were solubilized in $200 \mu \mathrm{l}$ of sample buffer (containing $8 \mathrm{M}$ urea, $2 \%$ Triton X-100, and $40 \mathrm{mM}$ DTT). The concentration of proteins was detected by the Quant-iT ${ }^{\mathrm{TM}}$ Protein Assay Kit (Invitrogen). The clear solution containing $100 \mu \mathrm{g}$ protein was resuspended in $250 \mu \mathrm{l}$ of the rehydration

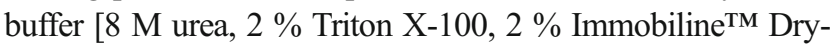
Strip gels buffer (IPG buffer) $\mathrm{pH} 3-10$, and $0.002 \%$ bromophenol blue]. Samples were loaded overnight onto $13 \mathrm{~cm}$ IPG strips, pH 3-10 (G.E. Healthcare) and rehydrated at $20^{\circ} \mathrm{C}$ for
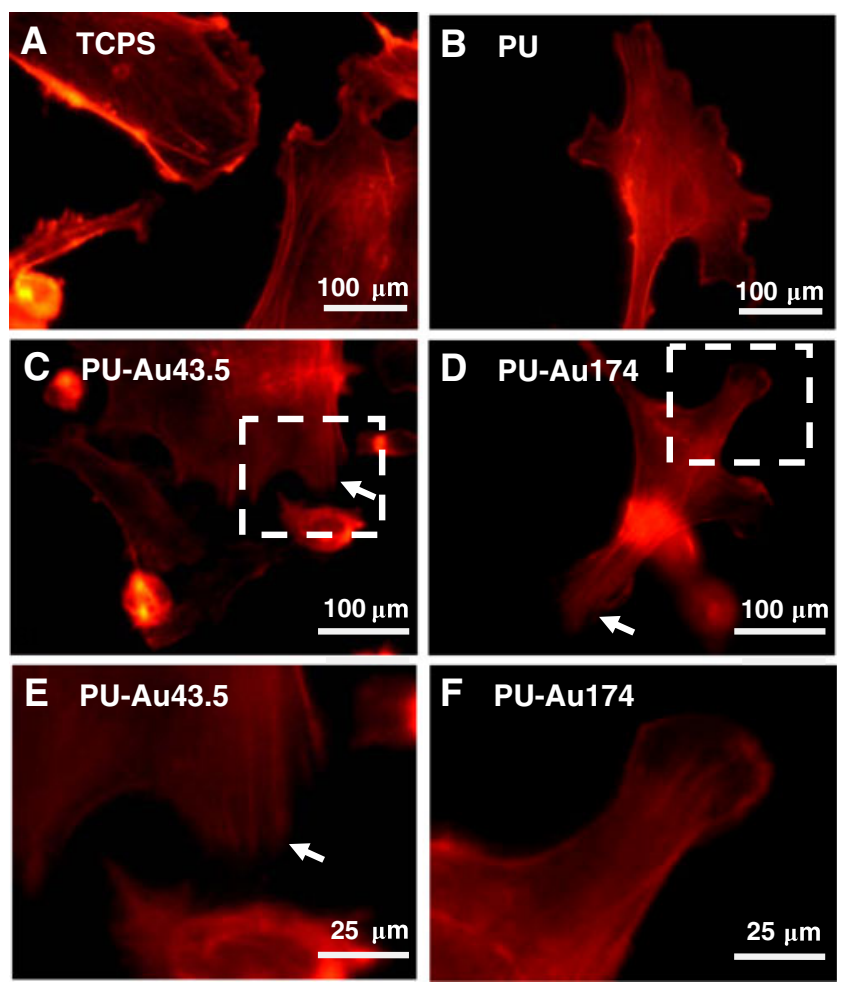

G

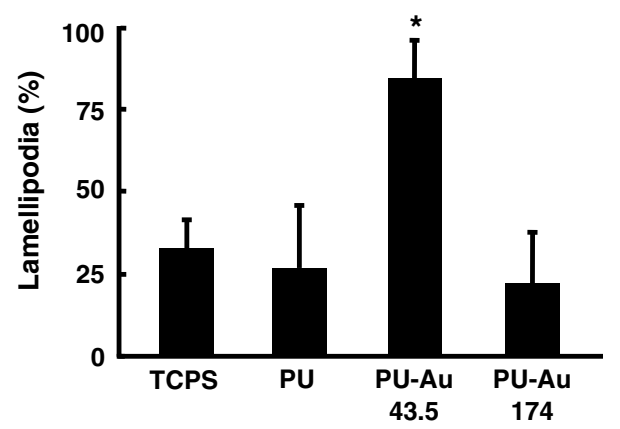

Fig. 1 The cell morphology of HUVECs on different substrates: a TCPS; b PU; c, e PU-Au 43.5 ppm; d, f PU-Au 174 ppm. Actin was stained by phalloidin. Arrows in c, d, e indicate the presence of lamellipodia, in contrast to the regular adhesion plaque demonstrated in $\mathbf{f}$. The areas marked as boxes in $\mathbf{c}, \mathbf{d}$ are shown in higher magnification in $\mathbf{e}, \mathbf{f}$. The number of lamellipodia normalized to the total number of contacts (i.e., percent chance of lamellipodia formation) is depicted in $\mathbf{g} .{ }^{*} p<0.05$ compared to the other groups
$12 \mathrm{~h}$. Sample strips were then resolved by isoelectric focusing using the following program: voltage set at $500 \mathrm{~V}$ for $2 \mathrm{~h}$, accumulation to $1,000 \mathrm{~V}$ for $2 \mathrm{~h}$, accumulation to $8,000 \mathrm{~V}$ for $5 \mathrm{~h}$, and at $8,000 \mathrm{~V}$ for $1 \mathrm{~h}$. Sample strips were then equilibrated for $15 \mathrm{~min}$ in each equilibration buffer (6 M urea, $75 \mathrm{mM}$ Tris$\mathrm{HCl}, 29.3 \%$ glycerol, $2 \%$ sodium dodecyl sulfate, $0.002 \%$ bromophenol blue) containing $10 \mathrm{mg} / \mathrm{ml} \mathrm{DTT} \mathrm{and} 25 \mathrm{mg} / \mathrm{ml}$ iodoacetamide. Following equilibration, strips were loaded onto $10 \%$ sodium dodecyl sulfate polyacrylamide gel electrophoresis (SDS-PAGE) and resolved in two dimensions at $45 \mathrm{~mA}$ per gel. Proteins on gels were visualized using a silver stain kit (Investigator Silver Stain Kit, Genomic Solutions) following the manufacturer's instructions [13, 14].

The protein expression profiles for each sample were scanned using the Imagescanner III (G.E. Healthcare) and the images were analyzed by the ImageMaster 2D Platinum computer software. During the image analysis, the software adjusted the location and expression according to the landmarks on the pictures which serve as the internal control.

In gel digestion and protein identification

The protein spots with the expression levels distinguished from the reference by more than $50 \%$ were excised from the gels and placed in the double-distilled water. The excised protein spots were then subjected to the in gel digestion and further analysis by matrix-assisted laser desorption/ionization time-of-flight (MALDI-TOF) mass spectrometry. Spectra were collected on an ABI Voyager-DE PRO MALDI-TOF mass spectrometer. The University of California, San Francisco database search program MS-Fit (http://prospector2.ucsf.edu/prospector/ mshome.htm) was employed to match the peptide $\mathrm{m} / \mathrm{z}$ values with the databases SwissProt and NCBInr.

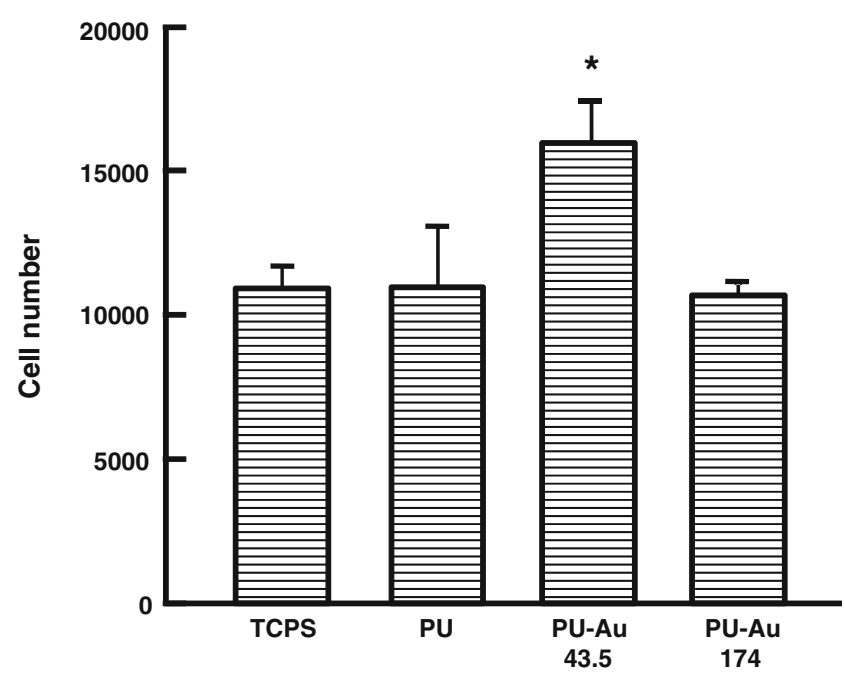

Fig. 2 The cell numbers of HUVECs for $48 \mathrm{~h}$ on different substrates. $* p<0.05$ compared to the other groups 
Gene expression and Western blot

Total RNA were extracted from cells cultured on each material for 2 days by the Trizol reagent (Invitrogen). Five hundred nanograms of mRNA was used as a template for cDNA synthesis using a reverse transcriptase (Fermentas). The zinc finger protein 792 (ZNF792), human SAM domain and HD domain-containing protein 1 (SAMHD1), human glucosamine-fructose-6-phosphate aminotransferase 1 (GFPT1), human transitional endoplasmic reticulum ATPase (also called valosin-containing protein [VCP]), and endothelial cell nitric oxide synthase (eNOS) genes were used as templates for mRNA level quantification and $\beta$-actin genes were used as control using the PCR Master
Fig. 3 The spots detected with distinct protein expression levels on each 2-DGE gel. The spots were indicated by the black circular contour on each gel. a The match ID 62 . b The match ID 66. L2 is one of the landmarks which serve as the basis for location adjustment and as an internal control for protein expression by the 2 DGE analysis software
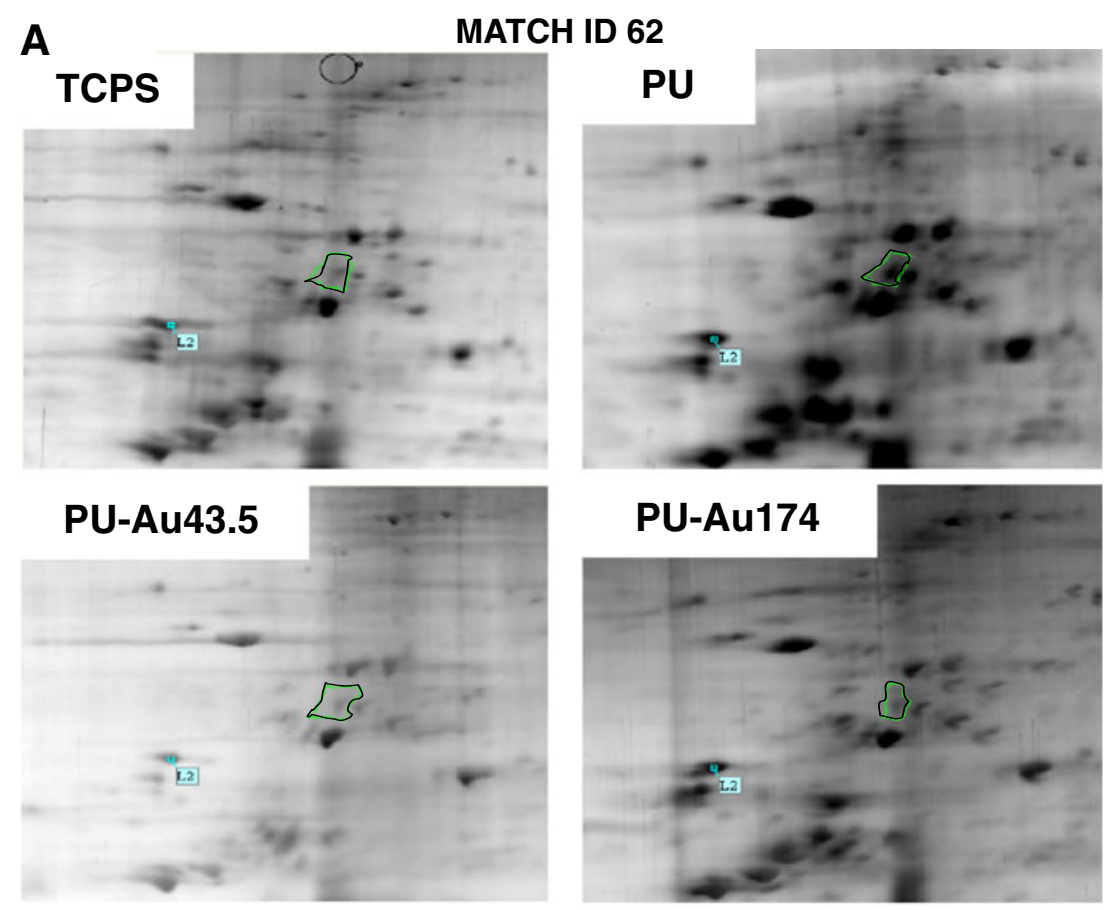

Approximate $\mathrm{Pl}=5.68, \mathrm{Mw}=56000$
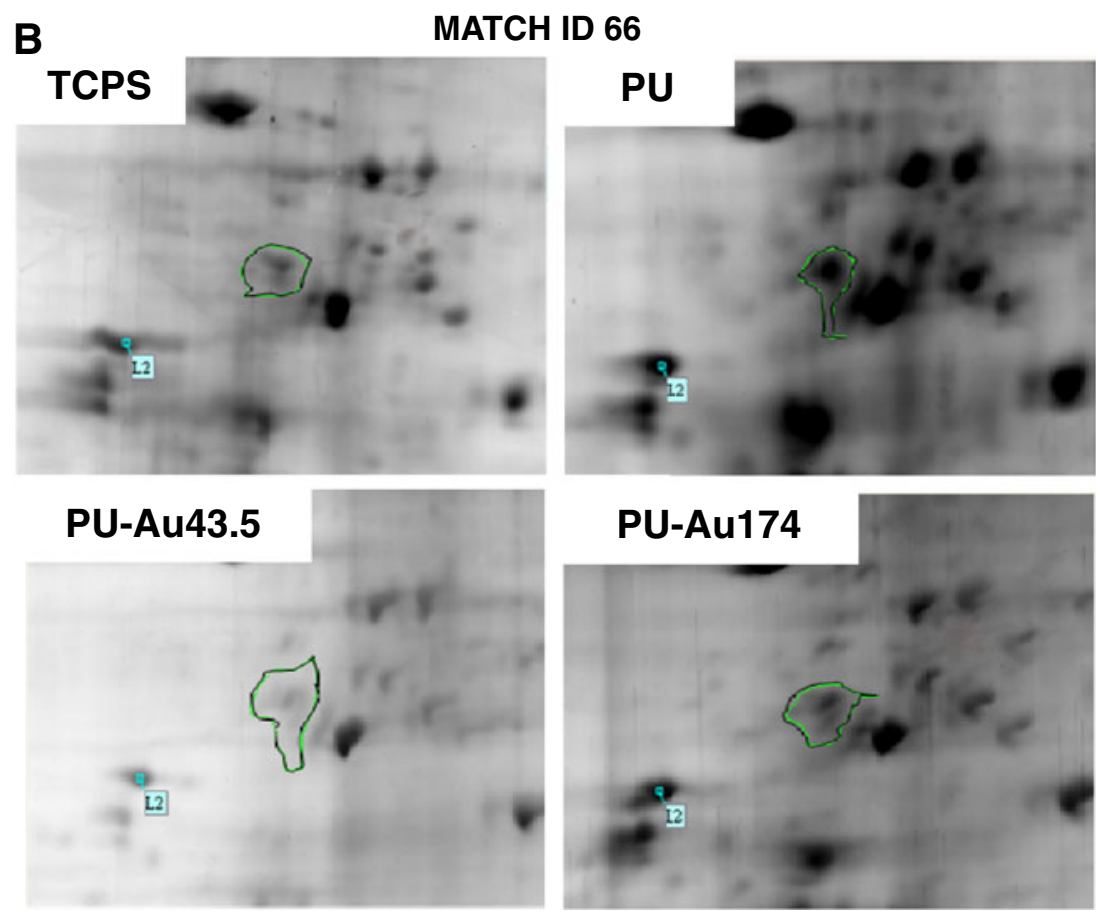

Approximate $\mathrm{PI}=5.52, \mathrm{Mw}=67000$ 
Mix (Gene Mark). The primers for ZNF792 were agactcctgtactgcgatgtga and tcacatatgcctcacacacaaa, with annealing template of $50{ }^{\circ} \mathrm{C}$. The primers for SAMHD1 were attacaggtgctggaggaaaaa and ttctctggcagaagttgtgaaa, with annealing template of $50{ }^{\circ} \mathrm{C}$. The primers for GFPT1 were ggaaaagttaaggcactggatg and ttcactccgtacaccaatcaac with annealing template of $50{ }^{\circ} \mathrm{C}$. The primers for VCP were tcctagccettattgcattgtt and gatcaagaagaagaaggctcca, with annealing template of $50{ }^{\circ} \mathrm{C}$. The primers for eNOS were gagatggtcaactatttcetgt and gaagcggatcttataactcttg, with annealing template of $53{ }^{\circ} \mathrm{C}$. The primers for $\beta$-actin were tccctcaagattgtcagcaa and agatccacaacggatacatt, with annealing template of $55^{\circ} \mathrm{C}$. The protein expression of VCP was analyzed by Western blot at $48 \mathrm{~h}$ post seeding. Proteins were separated by SDS-PAGE (10\% gels) and transferred to polyvinylidene difluoride membranes (Pall, USA). Membranes were blocked for $1 \mathrm{~h}$ with $5 \%$ milk in phosphatebuffered saline (PBS) containing $0.05 \%$ Tween-20 and then hybridized primary antibody with anti-VCP (Millipore, USA) or anti- $\beta$-actin (Millipore, USA) (1:1,000 dilution). After the membranes were washed with PBS containing $0.05 \%$ Tween-20, primary antibodies were detected using horseradish peroxidase (HRP)-conjugated secondary antibodies (Jackson ImmunoResearch, USA) (1:5,000 dilution) and signals were developed by the Immobilon Western Chemiluminescent HRP Substrate (Millipore).

In vivo biocompatibility

All use and care of animals in this study were approved by the university Animal Care and Use Committee with guidelines for the care and use of laboratory animals observed. Commercial indwelling venous PU catheters (external diameter $1.1 \mathrm{~mm}$ and length $32 \mathrm{~mm}$; Terumo, Germany) were employed. A few catheters were additionally coated with PU-Au $43.5 \mathrm{ppm}$. A few coated catheters were additionally cultured with rat ECs $\left(1 \times 10^{5}\right.$ cells per catheter $)$ on the surface for 3 days. To coat the catheters, the outer surface of the catheters was first activated by air plasma (Plasmatreat, Germany). The catheters were then immersed in the mentioned polymer solution for $5 \mathrm{~s}$, removed, and baked at $60{ }^{\circ} \mathrm{C}$ for $30 \mathrm{~min}$. The coated catheters were sterilized by $75 \%$ ethanol, rinsed, and placed in PBS. The rat ECs were isolated from rat caudal vena cava by cutting it into pieces and digested with collagenase II. These cells were identified by von Willebrand factor and eNOS. The model of rat jugular vein implantation followed a previous method [15] with modification. Adult Sprague-Dawley rats (400-450 g) were anesthetized before implantation. Animals were deeply anesthetized with isoflurane (Halocarbon, USA) throughout the surgical procedures. Each rat was shaved on the neck under aseptic conditions ( $70 \%$ alcohol). A small venotomy was made through which the catheter was introduced into the right jugular vein ( $30 \mathrm{~mm}$ depth from the venotomy). The external end of the catheter was closed by 4-0 nylon suture. The skin incision was closed layer by layer and the implanted catheter was not exposed. After 3 months, the rats were euthanatized by $\mathrm{CO}_{2}$ overdose treatment. The implants with surrounding tissue were excised and fixed in $10 \%$ natural formalin solution, embedded in paraffin, thinsectioned, and stained by hematoxylin and eosin (H\&E) for histological analysis using an optical microscope (Labophot-2, Nikon, Japan). The images were analyzed quantitatively by the Image Pro Plus 4.5 software.

\section{Statistics}

2-DGE data for PU-Au $43.5 \mathrm{ppm}$ were repeated three times and there were no significant differences among the three repeats. 2-DGE for TCPS, PU, and PU-Au 174 ppm was repeated twice and there were no significant differences among these groups. There was a significant difference between PU-Au 43.5 ppm and other groups.

\section{Results}

After the cells attached to the materials for $16 \mathrm{~h}$, their morphology had changed. As shown in Fig. 1c, most cells on PU-Au 43.5 ppm showed lamellipodia, as indicated by the arrow. Lamellipodial formation was not as frequently observed for cells on TCPS, PU, or PU-Au 174 ppm (Fig. 1a, b, d). Lamellipodia were cytoskeletal projections with extensively oriented actin bundles ("microspikes," arrows in Fig. 1c, d, e) in contrast to the regular cellmaterial contact (adhesion plaque) which has partially rounded margin and less oriented cytoskeleton (Fig. 1f). The percent chance of lamellipodial formation is shown in Fig. 1g. It was evident that cells on PU-Au $43.5 \mathrm{ppm}$ had

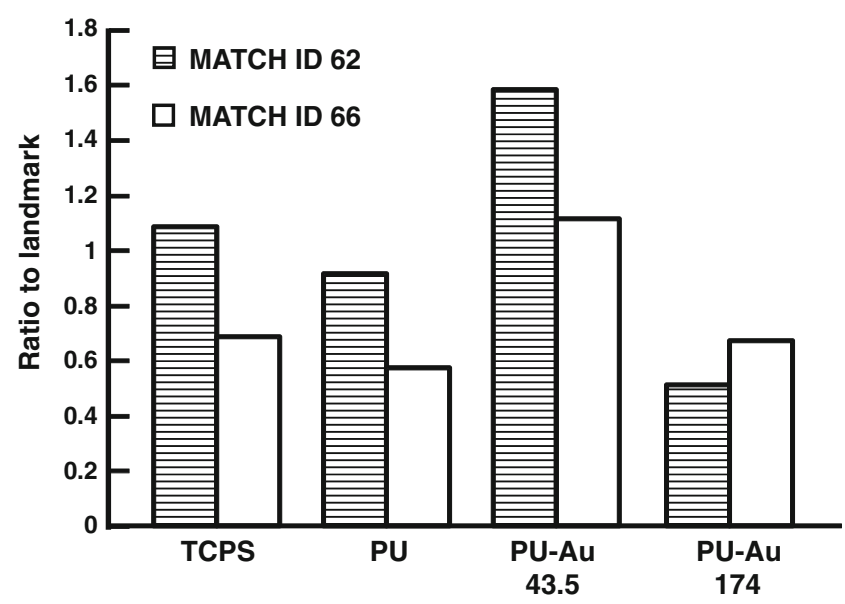

Fig. 4 The expression level of distinct protein spots relative to the landmark on each gel 
significantly more lamellipodial formation than cells on the other materials. The number of HUVECs on different materials after $48 \mathrm{~h}$ is shown in Fig. 2. PU-Au $43.5 \mathrm{ppm}$ also demonstrated the greatest number of cells.

Figure $3 \mathrm{a}, \mathrm{b}$ shows the spots detected with distinct protein expression levels, which were indicated by the black circular contour on each gel. The ID numbers were provided by the software. The match ID 62 corresponded to $\mathrm{PI}=5.68$ and $\mathrm{Mw}=$ 56,000 . The match ID 66 corresponded to $\mathrm{PI}=5.52$ and $\mathrm{Mw}=$
67,000 . Figure 4 shows the relative intensity of the spots with distinct protein expression levels on each gel for the match IDs 62 and 66. Figure 5 shows the fingerprint of protein spots by the mass spectrometer. A search by the databases SwissProt and NCBInr suggested that the match ID 62 may be ZNF792 and the match ID 66 may be VCP, SAMHD1, or GFPT1.

To identify the protein, we conducted the gene expression analysis by reverse transcription polymerase chain reaction to screen the possible proteins first. It was found that the

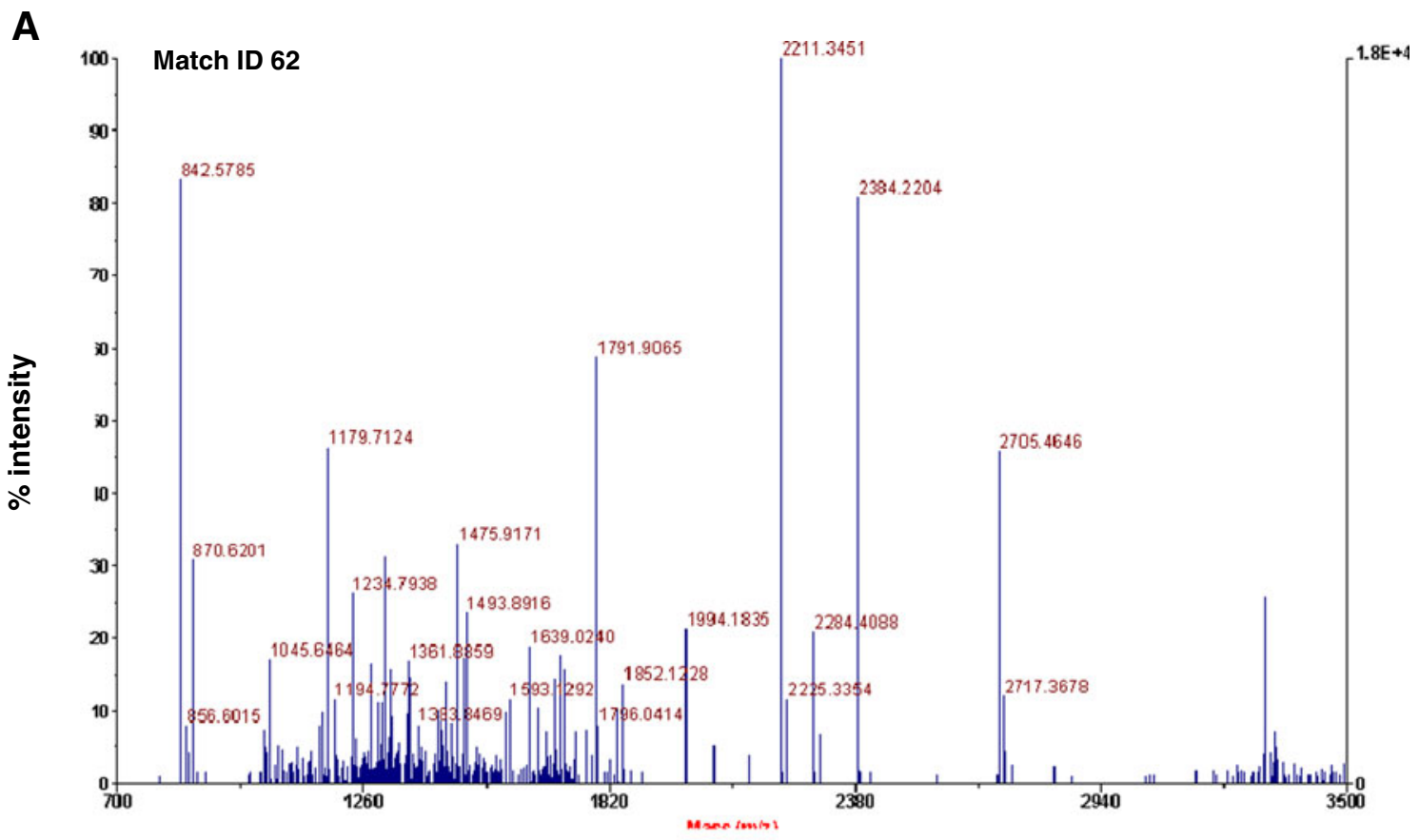

B

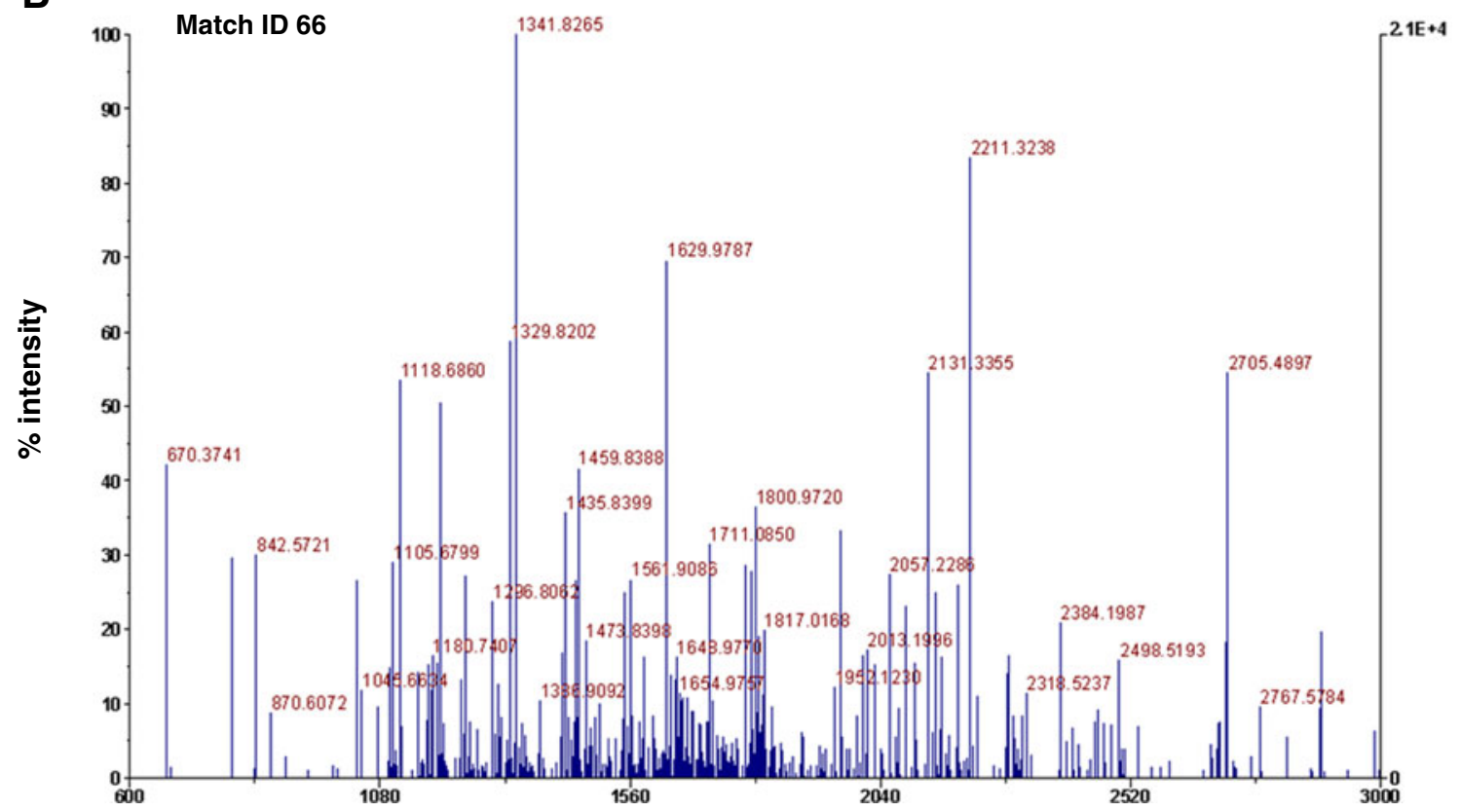

Fig. 5 The fingerprint of protein spots analysis by the mass spectrometer. a The match ID 62. b The match ID 66 
gene expression level for human ZNF792 was very low, suggesting that match ID 62 may not be this protein. The expression levels of SAMHD1 and GFPT1 were also very low. Only the gene expression of VCP was visible (data not shown). Therefore, we went further to identify VCP by Western blot. As shown in Fig. 6, the VCP protein expression profile followed a similar trend to that by 2-DGE, suggesting that match ID 66 may be the protein VCP.

The in vivo biocompatibility results of PU-Au are shown in Fig. 7. Since catheter insertion may elicit an inflammatory reaction of the vein, the venous wall thickening and fibrous capsule formation may serve as indexes for the evaluation of the biocompatibility of the catheters. The normal jugular vein (before catheter insertion) has an average wall thickness of $43 \mu \mathrm{m}$. After insertion, the control group (PU catheters; Fig. $7 \mathrm{a}, \mathrm{b}$ ) showed vein thickening and endothelium injury. The fibrous capsule was very thick and connected with the damaged endothelium. The average thickness of the venous wall was about $451 \pm 23 \mu \mathrm{m}$ and that of the fibrous capsule was about $123 \pm 4 \mu \mathrm{m}$ in the control group. On the other hand, PU-Au catheters caused less tissue injury than the control PU catheters. A lumen space existed between PU-Au-coated catheters and the intact endothelium (Fig. 7c, d), though some thrombus could be found. The average thickness of the venous wall was about $49 \pm 8 \mu \mathrm{m}$ and that of the fibrous capsule was about $19 \pm 1 \mu \mathrm{m}$ in the PU-Au catheter group. PU-Au catheters pre-seeded with ECs also showed less tissue injury than the control PU catheters (Fig. 7e, f). However, they did not perform better than the non-seeded PU-Au catheters. The average thickness of the venous wall was about $81 \pm 8 \mu \mathrm{m}$ and that of the fibrous capsule was about $44 \pm 7 \mu \mathrm{m}$. Considering the extents of vein thickening, fibrous capsule, and endothelium injury, the overall biocompatibility was ranked as PU-Au $\geq \mathrm{PU}-\mathrm{Au}+\mathrm{ECs}>$ control PU catheters.

\section{Discussion}

Traditional PU is solvent borne, which involves the use of a significant amount of toxic organic solvents. The current study employed a waterborne, more environmentally friendly process to produce PU and its nanocomposites. Based on the in vivo studies, vascular catheters coated with PU-Au were found to cause very minor wall thickening of the blood vessels, compared to the blank catheters. This result indicated that the PU-Au nanocomposite was anti-inflammatory, which increased the biocompatibility of the implants in vivo. Therefore, we suggested that PU-Au nanocomposites may be used as an elastic and anti-inflammatory coating material for cardiovascular devices such as stents.

In our previous in vitro study, PU-Au nanocomposites increased the migration of ECs through the PI3K/Akt and FAK signal transduction of bovine ECs [9]. In this study, the cytoskeleton of HUVEC was found to be more spread on $\mathrm{PU}-\mathrm{Au}$, which was consistent with the earlier observation. By 2-DGE, we tried to identify other downstream regulatory molecules for human vascular ECs in the present study. One of them was VCP. VCP is a multifunctional protein with ATPase activity. It is associated with many cellular functions such as membrane transport, protein folding, ubiquitin-proteasome degradation, apoptosis, as well as antigen processing and presentation to lymphocytes [16, 17]. It is also one of the direct regulatory targets of the Akt protein in the Akt pathway [18]. The Akt pathway influences the activity of eNOS which controls the synthesis of nitric oxide (NO) [19]. NO directly influences the proliferation, migration, and vascularization of ECs. The finding regarding the involvement of VCP suggested that PU-Au nanocomposites may upregulate the VCP expression of HUVECs to decrease their apoptosis [20]. VCP was a new protein identified by $2-$ DGE in this study. Therefore, the superior biocompatibility of PU-Au in vivo may be associated with the immunomodulation/anti-inflammation effects of this material through the stimulation of VCP expression. However, the actual role of VCP in PU-Au biocompatibility remains undefined. The contribution of VCP to biocompatibility will be investigated more carefully using technology such as VCP knockdown in the future studies.

2-DGE has been used to analyze the different patterns of protein expression between the differentiated and undifferentiated stem cells [21]. It has also been used to analyze the
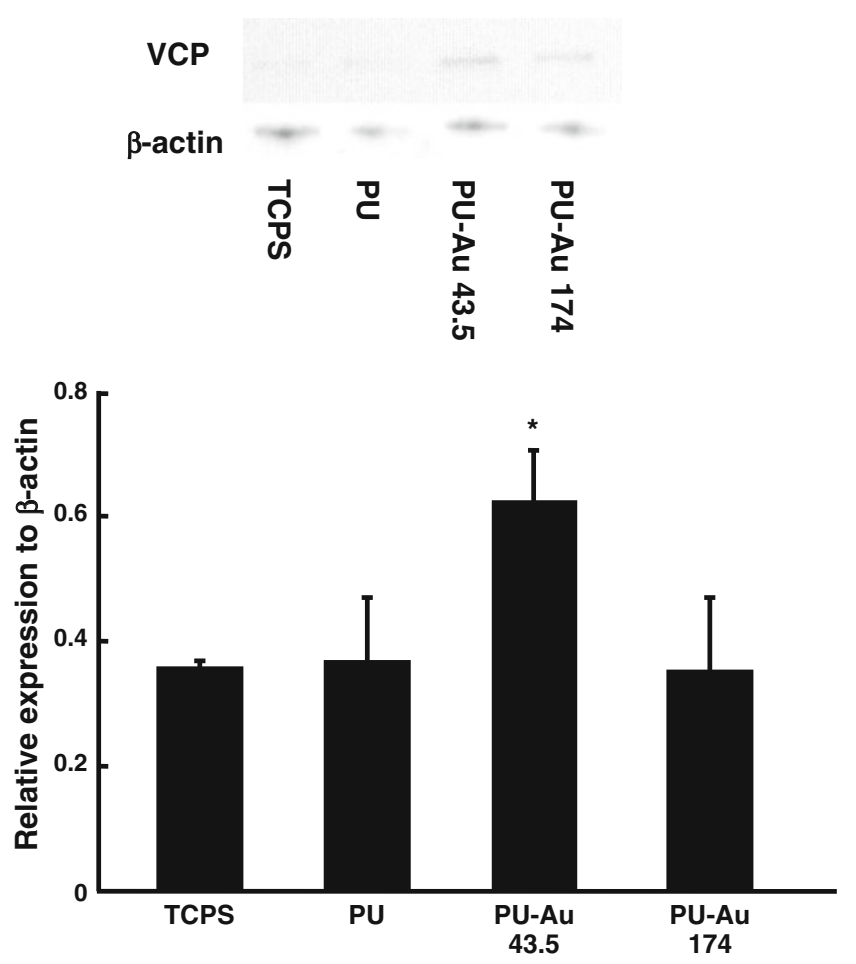

Fig. 6 The protein expression of the suspected protein, VCP. ${ }^{*} p<0.05$ compared to the other groups 
differences in protein expression for stem cells from various sources, as well as those with different differentiation status and donors [22, 23]. In addition, 2-DGE can be used to identify the biomarkers for disease diagnosis in human patients [24]. In this study, we tried to use this technology on analyzing the cellular physiology on different biomaterials, which was rarely reported. We expected to establish new proteins that were responsible for changed cell behaviors on biomaterials. The advantage of using 2-DGE as an analytic tool for this purpose is that abundant information can be obtained. Unlike the traditional cDNA array that directly determines the genes of interest, 2-DGE requires the use of MALDI-TOF to correctly identify the proteins. After protein identification by MALDI-TOF, confirmation action by Western blots is also needed [25]. Nevertheless, the gene expression profile obtained by cDNA array not necessarily reflects the actual protein expression. Therefore, 2-DGE is still a useful tool to discover new proteins involved in the cellular response to a material.

Literature has indicated that nanotopography can affect cell attachment, proliferation, migration, and differentiation [26]. Fibroblasts on 13-nm-high nanoislands showed upregulated cell attachment, proliferation, rearrangement of cytoskeleton, and extracellular matrix. Fibroblasts on 95-nm- high nanoislands, on the other hand, decreased cell attachment and cytoskeleton forming [27]. Studies using gene chips have pointed out that nanotopography can upregulate 584 genes which involve cytoskeleton, proliferation, gene transcription and translation, extracellular matrix secretion, and adjust cell signaling [28]. Biomaterials can regulate signaling pathways to promote wound healing. Using 2DGE to determine how materials affect wound repair, e.g., vascular repair, is a subject worth exploring.

Here in this study, we used 2-DGE as a tool to identify a protein molecule, VCP, in vascular ECs that was activated to various extents by different materials. The research tool 2DGE is normally used for feasibility studies. Further efforts may be focused on the anti-inflammatory mechanism of PUAu. Studies may be extended to use a PI3K inhibitor to determine the location of this protein in the signaling pathway, so the relation between the material and ECs can be further configured. This will aid in the design of a biomaterial that effectively enhances angiogenesis with less foreign body reaction.

The increased vascular wall thickness (overgrowth of vascular smooth muscle cells) is normally caused by EC injury, which was an undesired result in our in vivo study.
Fig. 7 The H\&E staining for the explanted catheters in $\mathbf{a}, \mathbf{b}$ the control PU catheter group; $\mathbf{c}, \mathbf{d}$ the group of $\mathrm{PU}-\mathrm{Au}$-coated catheters; $\mathbf{e}, \mathbf{f}$ the group of PU-Au-coated catheters pre-seeded with ECs
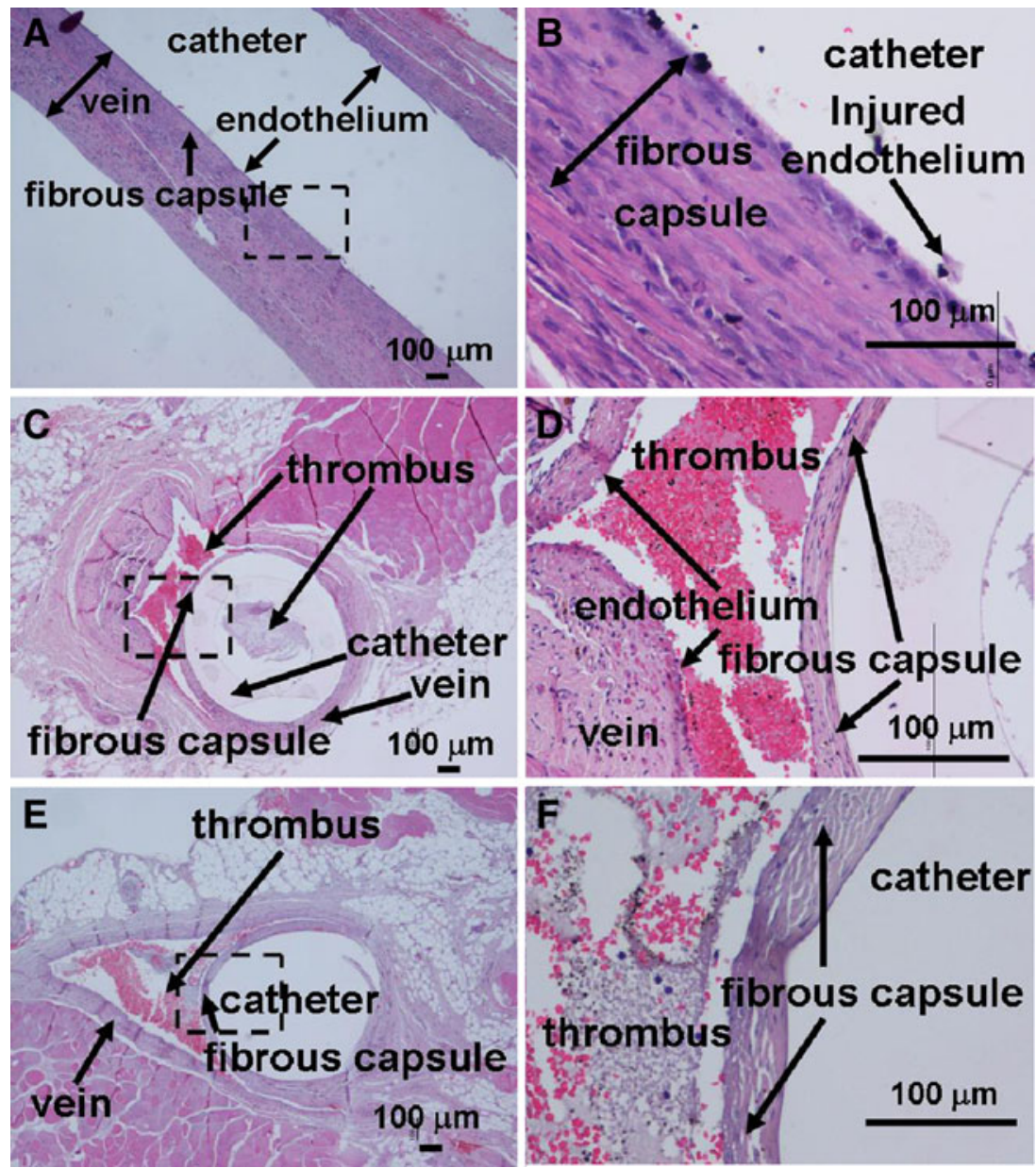
The vascular endothelium was not injured by the PU-Au catheters so no increase in wall thickness was observed. The rationale for seeding ECs was to further enhance the biocompatibility of PU-Au. Although PU-Au-coated catheters pre-seeded with ECs did perform better than the control PU group, they showed more foreign body reaction than those without pre-seeding. We thus hypothesized that the ECs preseeded on PU-Au may have prevented the direct contact of $\mathrm{PU}-\mathrm{Au}$ with the vascular lumen and decreased the positive effect of PU-Au on the host ECs in vivo.

AuNPs are widely considered safe. When mixed in materials, AuNPs do not induce oxidative DNA damage [29]. AuNPs possess certain antibacterial activities but do not trigger the reactive oxygen species (ROS) when killing bacteria [30], an antibacterial mechanism used by silver NPs. AuNPs can even scavenge ROS [31]. Adding a small amount of AuNPs in PU may enhance EC growth and provoke a smaller foreign body reaction without ROS damage. In addition to the free radical scavenging effect arising from the presence of AuNPs, PU-Au increases the expression of VCP that can prevent cell apoptosis. Both of these may contribute to the anti-inflammatory mechanism of PU-Au in this study. The anti-inflammatory effect of $\mathrm{Au}$-polymer nanocomposites makes them good coating materials for medical implants.

Acknowledgments This research was supported by the National Research Program for Nanoscience and Technology sponsored by the National Science Council (100-2120-M-002-006). Gold nanoparticles were provided by Gold Nanotech.

Open Access This article is distributed under the terms of the Creative Commons Attribution License which permits any use, distribution and reproduction in any medium, provided the original author(s) and source are credited.

\section{References}

1. Clark P, Connolly P, Curtis ASG, Dow JAT, Wilkisson CDW (1990) Topographical control of cell behavior: II. Multiple grooved substrata. Development 108:635-644

2. Clark P, Connolly P, Curtis ASG, Dow JAT, Wilkisson CDW (1987) Topographical control of cell behavior: I. Simole step cues. Development 99:439-448

3. Affrosssman S, Hemn G, O'Neill SA, Pethrick RA, Stamm M (1996) Surface topography and composition of deuterated polystyrene-poly(bromostyrene) blends. Macromolecules 29:5010-5016

4. Thapd AT, Webster TJ, Haberstroh KM (2003) Nano-structured polymers enhance bladder smooth muscle cell function. Biomaterials 24:2915-2926

5. Miller DC, Thapa A, Haberstroh KM, Webster TJ (2004) Endothelial and vascular smooth muscle cell function on poly(lactic-co-glycolic acid) with nano-structured surface features. Biomaterials 25:53-61

6. Hsu S, Yen H, Tsai C (2007) The response of articular chondrocytes to type II collagen-Au nanocomposites. Artif Organs 31:854-868

7. Hsu S, Tang C, Tseng H (2008) Gold nanoparticles induce surface morphological transformation in polyurethane and affect the cellular response. Biomacromolecules 9:241-248
8. Hsu S, Chang Y, Tsaie C, Fua K, Wang S, Tseng H (2011) Characterization and biocompatibility of chitosan nanocomposites. Colloids Surf B Biointerfaces 85:198-206

9. Hung H, Wu C, Chien S, Hsu S (2009) The behavior of endothelial cells on polyurethane nanocomposites and the associated signaling pathways. Biomaterials 30:1502-1511

10. Provansal M, Jorgensen C, Lehmann S, Roche S (2011) Two dimensional gel electrophoresis analysis of mesenchymal stem cells. Methods Mol Biol 698:431-442

11. Cruz-Topete D, Jorgensen JO, Christensen B, Sackmann-Sala L, Krusenstjerna-Hafstrøm T, Jara A, Okada S, Kopchick JJ (2011) Identification of new biomarkers of low-dose GH replacement therapy in GH-deficient patients. J Clin Endocrinol Metab 96:2089-2097

12. Zhang W, Liu G, Tang F, Shao J, Lu Y, Bao Y, Yao H, Lu C (2011) Pre-absorbed immunoproteomics: a novel method for the detection of Streptococcus suis surface proteins. PLoS One 6:e21234

13. Guo X, Zhao C, Wang F, Zhu Y, Cui Y, Zhou Z, Huo R, Sha J (2010) Investigation of human testis protein heterogeneity using two-dimensional electrophoresis. J Androl 31:419-429

14. Thompson LJ, Wang F, Proia AD, Peters KG, Jarrold B, Greis KD (2003) Proteome analysis of the rat cornea during angiogenesis. Proteomics 3:2258-2266

15. Klement P, Du YJ, Berry LR, Tressel P, Chan AKC (2006) Chronic performance of polyurethane catheters covalently coated with ATH complex: a rabbit jugular vein model. Biomaterials 27:5107-5117

16. Dai RM, Li CC (2001) Valosin-containing protein is a multiubiquitin chain-targeting factor required in ubiquitin-proteasome degradation. Nat Cell Biol 3:740-744

17. Larsen CN, Price JS, Wilkinson KD (1996) Substrate binding and catalysis by ubiquitin C-terminal hydrolases: identification of two active site residues. Biochemistry 35:6735-6744

18. Vandermoere F, El Yazidi-Belkoura I, Slomianny C, Demont Y, Bidaux G, Adriaenssens E, Lemoine J, Hondermarck H (2006) The valosin-containing protein (VCP) is a target of Akt signaling required for cell survival. J Biol Chem 281:14307-14313

19. Karar J, Maity A (2011) PI3K/AKT/mTOR pathway in angiogenesis. Front Mol Neurosci 4:51

20. Wójcik C, Yano M, DeMartino GN (2004) RNA interference of valosin-containing protein $(\mathrm{VCP} / \mathrm{p} 97)$ reveals multiple cellular roles linked to ubiquitin/proteasome-dependent proteolysis. J Cell Sci 117:281-292

21. Zhang AX, Yu WH, Ma BF, Yu XB, Mao FF, Liu W, Zhang JQ, Zhang XM, Li SN, Li MT, Lahn BT, Xiang AP (2007) Proteomic identification of differently expressed proteins responsible for osteoblast differentiation from human mesenchymal stem cells. Mol Cell Biochem 304:167-179

22. Kheterpal I, Ku G, Coleman L, Yu G, Ptitsyn AA, Elizabeth Floyd Z, Gimblez JM (2011) Proteome of human subcutaneous adipose tissue stromal vascular fraction cells versus mature adipocytes based on DIGE. J Proteome Res 10:1519-1527

23. Lazzarotto-Silva C, Binato R, Rocher BD, Costa JA, Pizzatti L, Bouzas LF, Abdelhay E (2009) Similar proteomic profiles of human mesenchymal stromal cells from different donors. Cytotherapy 11:268-277

24. Xu G, Hou CR, Jiang HW, Xiang CQ, Shi N, Yuan HC, Ding Q, Zhang YF (2010) Serum protein profiling to identify biomarkers for small renal cell carcinoma. Indian J Biochem Biophys 47:211-218

25. McNamara LE, Dalby MJ, Riehle MO, Burchmore R (2010) Fluorescence two-dimensional difference gel electrophoresis for biomaterial applications. J R Soc Interface 7:S107-S118

26. Dalby MJ, Riehle MO, Johnstone H, Affrossman S, Curtis AS (2004) Investigating the limits of filopodial sensing: a brief report using SEM to image the interaction between $10 \mathrm{~nm}$ high nano-topography and fibroblast filopodia. Cell Biol Int 28:229-236 
27. Dalby MJ, Pasqui D, Affrossman S (2004) Cell response to nanoislands produced by polymer demixing: a brief review. IEE Proc Nanobiotechnol 151:53-61

28. Dalby MJ, Riehle MO, Sutherland DS, Agheli H, Curtis ASG (2004) Use of nanotopography to study mechanotransduction in fibroblasts - methods and perspectives. Eur J Cell Biol 83:159169

29. Nelson BC, Petersen EJ, Marquis BJ, Atha DH, Elliott JT, Cleveland

D, Watson SS, Tseng IH, Dillon A, Theodore M, Jackman J (2011)
NIST gold nanoparticle reference materials do not induce oxidative DNA damage. Nanotoxicology. doi:10.3109/17435390.2011.626537

30. Cui Y, Zhao Y, Tian Y, Zhang W, Lü X, Jiang X (2012) The molecular mechanism of action of bactericidal gold nanoparticles on Escherichia coli. Biomaterials 33:2327-2333

31. Srinivas P, Patra CR, Bhattacharya S, Mukhopadhyay D (2011) Cytotoxicity of naphthoquinones and their capacity to generate reactive oxygen species is quenched when conjugated with gold nanoparticles. Int J Nanomedicine 6:2113-2122 